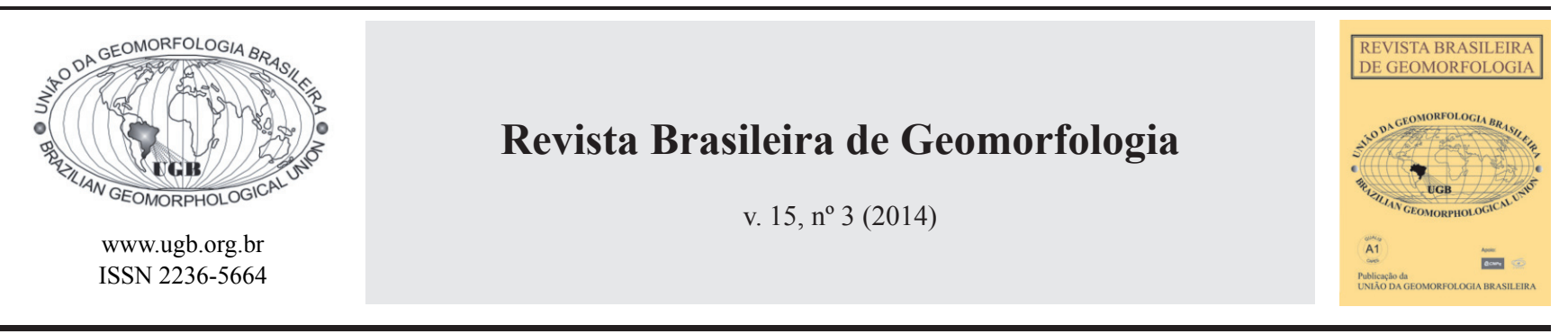

\title{
RELEVO CÁRSTICO EM ROCHAS SILICICLÁSTICAS: UMA REVISÃO COM BASE NA LITERATURA
}

\section{KARSTIC RELIEF IN SILICICLASTIC ROCKS: A REVISION ON THE BASIS OF THE LITERATURE}

Fabiana Fabri

Departamento de Geografia, Universidade Federal de Minas Gerais. Av. Antônio Carlos, 6.627, Pampulha, Belo Horizonte/MG, Cep: 31270-901, Brasil.

E-mail:fpfabri@yahoo.com.br

Cristina Helena Ribeiro Rocha Augustin

Departamento de Geografia, Universidade Federal de Minas Gerais. Av. Antônio Carlos, 6.627, Pampulha, Belo Horizonte/MG, Cep: 31270-901, Brasil.

E-mail: chaugustin@hotmail.com

Augusto Sarreiro Auler

Instituto do Carste.

Rua Brasópolis, 139, Floresta, Belo Horizonte/MG, Cep: 30360-240, Brasil.

E-mail:aauler@gmail.com

\section{Informações sobre o Artigo}

Data de Recebimento:

25/05/2012

Data de Aprovação:

$30 / 06 / 2014$

\section{Palavras-chave:}

Formas cársticas, rochas siliciclásticas, revisão da literatura.

\section{Keywords:}

Karst landforms, siliciclastic rocks, revision of the literature.

\section{Resumo:}

O relevo cárstico foi durante muito tempo associado à presença de rochas carbonáticas, em função da predisposição das mesmas à atuação dos processos de dissolução. Estudos recentes vêm mostrando, no entanto, que feições semelhantes àquelas desenvolvidas nessas litologias estão também presentes em outros tipos de substrato rochoso, em especial nas siliciclásticas, desde que haja condições para que a dissolução e a retirada do material ocorram. Essas feições são consideradas como cársticas, uma vez que os processos de dissolução exercem papel fundamental no desenvolvimento das mesmas. Esta interpretação não constitui consenso entre os estudiosos, pois para alguns, essas feições não são resultantes predominantemente da dissolução, pois é baixa a solubilidade do quartzo. No Brasil, este tipo de rocha cobre grandes extensões territoriais, o que torna o entendimento dos fatores envolvidos na sua elaboração, bem como dos seus mecanismos associados, muito importantes para conhecer e compreender a evolução do relevo destas vastas áreas. Por se tratar de tema relativamente novo, sua discussão possibilita a difusão, e amplia o escopo desses estudos. $\mathrm{O}$ artigo busca contribuir para esse objetivo, ao apresentar com base na literatura, os principais aspectos conceituais e analíticos sobre o tema, com ênfase nas cavernas em rochas siliciclásticas. 


\section{Abstract:}

Karst relief has usually been associated to the presence of carbonate due to its predisposition for dissolution caused by chemical weathering. The results of recent researches have shown, however, that similar features to those developed in carbonates are also present in other lithologies, especially in siliciclastic ones once the right conditions for their development exist. However, there is no full agreement between the researchers in assuming that dissolution is really the main process involved in the development of this type of relief due to the low solubility of quartz. In Brazil, siliciclastic rocks outcrop cover extensive areas highlighting the importance of understanding the factors involved in the genesis of the karstic features as a basis to understand the landscape evolution on these vast areas. As there are still relatively few studies about karst in non-carbonate rocks, research on this aspect became an important subject that can help to increase the awareness and comprehension about this type of relief. This work intends to contribute to the discussion by presenting a conceptual and analytical synthesis based on the literature about non-carbonate karst features with emphasis on siliciclastic rocks.

\section{Introdução}

Os estudos cársticos historicamente dizem respeito às rochas carbonáticas, o que explica a forte tendência que ainda existe em associar o termo a esta litologia. No entanto, na medida em que as pesquisas avançam para outros tipos de rochas, inclusive aquelas quimicamente mais resistentes como, por exemplo, as quartzíticas e as areníticas, surgem propostas no sentido de conceituar o termo carste de maneira mais ampla, levando em consideração para o seu desenvolvimento não somente $o$ fator litológico, mas também evidências morfológicas e químicas (MARTINI, 1979, 1984; TWIDALE, 1987; YOUGER \& STUNNEL, 1995; WRAY, 1997; ROMANÍ \& VAQUERO, 2007; GONÇALVES et al., 2011).

Descrição de relevo semelhante ao cárstico do calcário, mas desenvolvido em rochas siliciclásticas, já vinha sendo reportada na literatura desde a década de 1950 (RENAULT, 1953). Entretanto, WHITE et al. (1996) e SZCERBAN \& URBANI (1974) foram os primeiros autores a realizarem trabalhos mais sistemáticos sobre este tipo de carstificação, abrindo um novo campo para as investigações geomorfológicas.

Um dos principais aspectos responsáveis pela dificuldade na identificação da dissolução como um processo atuante em rochas silisiclásticas, se deve ao fato destas terem sido, por muito tempo, consideradas inertes do ponto de vista do intemperismo químico, e também porque estes processos são temporalmente muito longos (WRAY, 1997). Krauskopf (1972) ressalta que esta ideia foi aceita durante muito tempo com base no pressuposto de que o quartzo, principal mineral componente dessas rochas, teria pouca ou nenhuma susceptibilidade à dissolução em condições naturais de temperatura e $\mathrm{pH}$ (TRICART \& CAILLEUX, 1972; AUBRECHT et al., 2011). Este fato induziu a uma tendência generalizada na literatura em se referir a tais formas como um pseudocarste (POUYLLAU, 1985; POUYLLAU \& SEURIN, 1985; FABRI 2011; FABRI \& AUGUSTIN, 2012).

Estudos mais recentes contestam essa denominação sob o argumento de que o termo "pseudo" não tem grande significado no que diz respeito à evolução desse tipo de relevo, podendo levar a uma interpretação equivocada de que não se trata, de fato, de feições cársticas (SELF \& MULLAN, 1996). O avanço da pesquisa nesse tipo de relevo, bem como a descoberta de que este é frequente em rochas siliciclásticas, levou Urbani (1986a) a defender a necessidade da utilização de denominações específicas para formas cársticas nos quartzitos, tais como paracarste, carste quartzítico e carste quartzítico.

Ao mesmo tempo, o argumento de que as rochas siliciclásticas sejam inertes do ponto de vista dos processos químicos de dissolução tem sido cada vez mais debatido, não encontrando respaldo em vários estudos. Exemplo disso são os trabalhos de Martini $(1979,1984)$, que demonstram a ocorrência da ação química nos grãos de quartzo associada à existência da carstificação em quartzitos e meta-arenitos no continente africano. Seus resultados indicam, ainda, que há indícios de que a erosão através do piping seja o principal mecanismo responsável, em termos quantitativos, pela remoção de partículas das rochas siliciclásticas.

Foi a partir do trabalho de Jennnigs (1983) que o termo carste passou a ser mais amplamente empregado. Ele defende a ideia de que as feições cársticas devem ser 
compreendidas em termos dos processos e não apenas da litologia, e argumenta que o processo de dissolução desempenha um papel crítico, mas não necessariamente dominante no desenvolvimento das formas e drenagens características desse relevo.

Atualmente, tornou-se mais frequente na literatura a presença de artigos que discutem evidências do carste em outras litologias que não as carbonáticas, nos quais a perspectiva de Jennings (op cit.) sobre a definição de carste é compartilhada (URBANI, 1986b; YOUNG \& YOUNG, 1992; SELF \& MULLAN, 1996; WRAY, 1997a; WRAY, 1997b; WRAY, 1997c; DOERR, 1999; WRAY, 2009; SILVA, 2004; FABRI, 2011; UAGODA et al., 2011; FABRI \& AUGUSTIN, 2013; SAURO et al., 2013).

Em decorrência desses avanços, o termo pseudo-carste vem sendo bastante questionado (SELF \& MULLAN, 1996; WRAY, 1997; MARTINI, 2004). Glazek (2006) e Hardt et al. (2009) chegaram a propor sua extinção da literatura por apresentar um significado pouco preciso e que provoca mal-entendidos. Esses autores destacam a importância na distinção das feições que se assemelham às cársticas, mas que são evidentemente diferentes destas em termos de processos de formação. Sugerem a adoção de outros termos, como vulcanocárstico, ou carste em quartzito, para identificar mais precisamente os processos envolvidos. Contudo, não deixam claro qual a contribuição que esta distinção traria, uma vez que, na proposta apresentada, a ênfase continua sendo a semelhança das formas e o meio no qual elas ocorrem. Segundo esses autores, o termo vulcanocartse, por exemplo, seria aplicado às feições do tipo cárstica, porém associadas também a processos vulcânicos, e nem sempre envolvendo a dissolução. É interessante, assinalar que, neste caso específico, a utilização da terminologia pseudo-carste não seria de fato totalmente equivocada, uma vez que se refere às formas de relevo semelhantes às cársticas, mas que não envolvem a dissolução como fator fundamental na sua formação. Isto não significa que denominações específicas indicando com precisão o meio no qual essas formas ocorrem, tais como criocarste, produzido por degelo em região de permafrost, ou mesmo, vulcanocarste associado a materiais vulcânicos, conforme defendido por Hardt et al. (2009), não devam, ou possam, ser utilizadas.

\section{Gênese e Evolução de Cavernas em Rochas Sili- ciclásticas}

\subsection{Dissolução das rochas siliciclásticas}

Diversas hipóteses foram propostas para explicar o desenvolvimento das feições cársticas em rochas siliciclásticas. O modelo de Martini (1979) é o mais aceito, embora alguns autores, como Aubrecht et al.(2011), tenham argumentado que uma fase inicial da dissolução do quartzo pode não ser essencial, ou até mesmo estar ausente, no desenvolvimento de grandes sistemas de cavernas em quartzito, nos quais predominariam os aspectos estruturais das rochas, com o predomínio de processos de retirada do material rochoso por piping em camadas não litificadas dos tepuis venezuelanos.

De acordo com Martini (1979), o processo de carstificação nessas rochas abrange essencialmente duas fases. A primeira é dominada pelo intemperismo químico, na qual a dissolução atua no domínio intergranular dissolvendo o cimento composto pela sílica amorfa, promovendo a individualização dos grãos de quartzo. Após esta fase de desagregação química, denominada "arenização", ocorre uma segunda, controlada pelos processos erosivos, na qual os grãos de quartzo podem ser evacuados, principalmente através do processo de piping.

Os compostos de sílica estão presentes em todas as águas naturais. No entanto, a maior parte provém do intemperismo químico dos minerais silicatados, tais como feldspatos e micas que, normalmente, são mais solúveis do que a sílica pura, e não da dissolução do próprio quartzo (YOUNG \& YOUNG, 1992). Segundo Wray (1997b), dentre os oito minerais compostos de sílica pura, apenas três são de importância imediata para o processo de carstificação devido à sua frequente ocorrência em rochas siliciclásticas: quartzo, sílica amorfa e opala-A. Enquanto quartzo possui arranjo cristalino, os dois últimos são amorfos.

O intemperismo da sílica ocorre por meio da hidratação formando sílica ácida, o que pode ser representado através da seguinte equação (HENDERSON, 1982):

$$
\mathrm{SiO}_{2}(\mathrm{~s})+2 \mathrm{H}_{2} \mathrm{O}=\mathrm{H}_{4} \mathrm{SiO}_{4}(\mathrm{aq}) \text { a } 25^{\circ} \mathrm{C}
$$


Para Yariv \& Cross (1979), a dissolução da sílica depende das propriedades da solução tais como: o estado no qual a sílica se encontra (grau de cristalização ou fase amorfa), $\mathrm{pH}$, tempo das reações químicas; temperatura; presença de vários sais, e compostos orgânicos e inorgânicos. Szcerban e Urbani (1974) ressaltam que a resistência da sílica ao intemperismo químico é bastante variável. Isto decorre dos diferentes estados morfológicos na qual ela se encontra. Conforme demonstra a Tabela 1 , em águas naturais a sílica a $25^{\circ} \mathrm{C}(\mathrm{ppm})$ no seu estado amorfo apresenta maior grau de solubilidade quando comparada à sílica cristalina.

A elevação da temperatura promove a aceleração da maioria das reações químicas, resultando em um maior grau de dissolução. O mesmo pode ser observado no caso da sílica (Tab. 1). Esse fato levou muitos pesquisadores a crer que em ambientes naturais, as feições cársticas em rochas siliciclásticas só se desenvolveriam em regiões tropicais úmidas. Há evidências de que essas feições não se restringem a essas regiões. Wray (1997b; 2010), por exemplo, aponta o registro de ocorrência desse fenômeno tanto em ambientes mais frios, quanto em regiões temperadas e até mesmo em latitudes subpolares, especialmente onde não se tem evidência de clima tropical pretérito.

Tabela 1: Solubilidade das várias formas da sílica em águas naturais em função temperatura. Fonte: Szcerban \& Urbani (1974).

\begin{tabular}{|c||c|c|c||}
\hline & \multicolumn{3}{|c|}{ Solubilidade (ppm) } \\
\hline \hline Temperatura & $\mathbf{2 5}^{\circ} \mathbf{C}$ & $\mathbf{1 0 0}^{\circ} \mathbf{C}$ & $\mathbf{2 0 0}^{\circ} \mathbf{C}$ \\
\hline Quartzo & 6 & 49 & 268 \\
\hline \hline Cristobalita & 17 & 83 & 322 \\
\hline Calcedônia & 27 & 125 & 465 \\
\hline Sílica Gel & 115 & 360 & 930 \\
\hline
\end{tabular}

De acordo com Krauskopf (1972), a solubilidade da sílica independe do $\mathrm{pH}$, caso este se situe entre 2 e 9 , tendendo a se tornar realmente solúvel apenas em condições de pH superiores a 9 (Figura 1). Em função dessas limitações, baixas taxas de dissolução, em geral inferiores a 10ppm, podem ser esperadas nas águas de arenitos e quartzitos, (GALÁN, 1991; WRAY, 1997a; MECCHIA\& PICCINI, 1999; WIEGAND et al., 2004).
Isto é especialmente válido no caso dos quartzitos, tendo em vista o fato de que em meios naturais, valores de pH igual ou superior a 9, são raramente alcançados nos maciços rochosos destes tipos de rochas, seja em águas superficiais ou subterrâneas (GALÁN, 1991).

Não existem, todavia, evidências irrefutáveis de que o $\mathrm{pH}$ e a temperatura representem fatores determinantes no desenvolvimento de feições cársticas em rochas siliciclásticas. A ocorrência dessas formas predominantemente em regiões tropicais parece estar associada prioritariamente à disponibilidade hídrica, em função da baixa solubilidade da sílica (AULER, 2004). Além disso, não se tem registro de carstificação dessas rochas em zonas áridas (GALÁN, 1991).

Outro aspecto presente nas discussões sobre o tema refere-se à capacidade ou não dos ácidos orgânicos influenciarem a taxa de dissolução da sílica (BENNET, 1991; BENNET et al., 1998; DREVER et al., 1996; VIERS et al., 1997; BENNET et al., 1998; WIEGAND et al., 2004). Young (1988) menciona a possibilidade de que a velocidade da dissolução da sílica possa ser acelerada com a presença de elevadas concentrações de cloretos. Resultados apresentados por Icehower et al. (2000) revelam que as taxas de dissolução da sílica podem ser elevadas em até 21 vezes, quando é introduzido $\mathrm{NaCl}$ em uma solução, mesmo em pequenas concentrações. Pelo fato dos resultados terem alcançados valores similares, tanto para a sílica amorfa como para o quartzo, esses autores assumem que outros solutos presentes na água (potássio, magnésio e cálcio), também possam ser capazes de acelerar a superfície de reatividade da sílica amorfa na dissolução.

Há autores que sugerem as bactérias como elementos que exercem um papel importante na dissolução de algumas rochas siliciclásticas (WILLEMS et al., 1998). Este é o caso de Brehm et al. (2004), que identificaram impressões de microorganismos (bactérias e cianobactérias) nas superfícies dos grãos de quartzo analisados nos tepuis venezuelanos. Viles \& Pentecost (1994), também relataram a probabilidade de que liquens estejam envolvidos no processo de intemperismo das rochas areníticas e quartzíticas. Lundberg et al. (2010a; 2010b) indicam a importância dos processos bioquímicos que, segundo eles, representam o fator dominante no controle do desenvolvimento de microfeições encontradas na caverna arenítica Charles Brewer, nos tepuis do sudeste da Venezuela. 


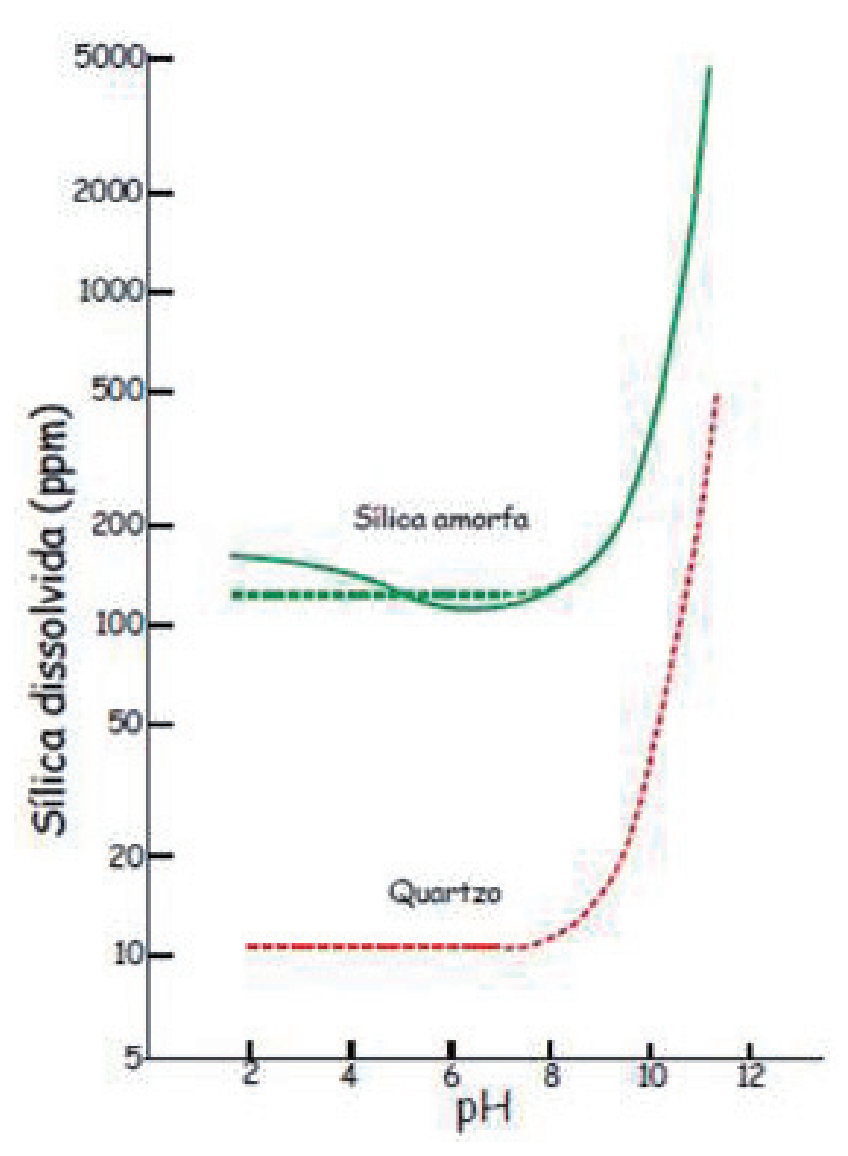

Figura 1 - Gráfico mostrando a solubilidade da sílica em função do pH. Fonte: Krauskopf (1972).

A contribuição de bactérias no processo de dissolução da sílica foi identificada ainda em espeleotemas compostos principalmente de opala - A. Para Romaní et al. (2003) e Lundberg et al. (2010a; 2010b), espeleotemas em cavernas siliciclásticas teriam origem biogenética, nos quais bactérias induzem a dissolução dos grãos de quartzo, transformando este mineral em sílica biogênica (opala $-\mathrm{A}$ ), que é quinze vezes mais solúvel do que o quartzo (KRAUSKOPF, 1972; BENNET, 1991). Mesmo assim, Lundberg et al. (2010a) destacam o crescimento muito lento dos denominados "biotemas" de sílica encontrados e datados nos Cueva Charles Brewer, nos tepuis da Venezuela.

Em função da estabilidade química da sílica, que resulta em sua baixa alterabilidade, o relevo cárstico em quartzitos e arenitos é interpretado como tendo idades relativamente elevadas, principalmente quando comparado com o carste carbonático. Galán (1991) sugere que seriam necessários cerca de dois milhões de anos para o início da formação de um sistema cárstico silicoso.
Piccini \& Mecchia (2009) também indicam o tempo como um dos principais fatores envolvidos no desenvolvimento de cavernas, em especial em áreas com águas levemente ácidas. Para eles, levando em consideração as taxas de perdas na área pesquisada de Sima Aonda, na Venezuela, teriam sido necessários no mínimo 10Ma para que se formasse um relevo cárstico, partindo-se do princípio de que o clima tenha permanecido estável durante este período. Esses autores, no entanto, não descartam a possibilidade de que o sistema cárstico estudado possa ser ainda mais antigo (20 a 30Ma).

Szcerban \& Urbani (1974) e Galán (1991) sugerem que, tendo em vista o grande número de registro de carstificação em rochas siliciclásticas em regiões intracratônicas, a estabilidade tectônica deva ser também considerada como um fator relevante, associado à questão das idades elevadas dessas formas. Para alguns pesquisadores, a carstificação dessas rochas, seria resultado de um conjunto de processos, atuando de maneira contínua ao longo de muito tempo (GALÁN, 1991; WRAY, 1997b; SILVA, 2004).

Há os que defendam a ideia de que a dissolução de cavernas em rochas siliciclásticas ocorra em uma matriz mais solúvel que, em alguns casos, sustentam os grãos de quartzo, resultando na evolução dessas formas em um tempo mais curto (URBANI, 1986b; YOUNG, 1988; GALÁN, 1991; YOUNGER et al., 1995). Neste contexto, estudos desenvolvidos em cavernas quartzíticas no Brasil têm enfatizado a importância da presença de constituintes mais facilmente intemperizáveis da rocha, de maneira a possibilitar desenvolvimento inicial de rotas de fluxo subterrâneo. Corrêa Neto (1997) foi o primeiro a sugerir que a alteração de micas, feldspatos e minerais de argila poderia ser um mecanismo importante na gênese de cavernas na Serra do Ibitipoca, sudeste do Brasil. Melo \& Giannini (2007) também sustentam que a dissolução da caulinita constitui o principal mecanismo de formação de relevos cársticos na Formação Furnas do sul do Brasil. Análises petrográficas realizadas nas cavernas quartzíticas no sudeste da Serra do Espinhaço (FABRI, 2011; FABRI \& AUGUSTIN, 2012), revelam que níveis de mica (sericita) orientados no plano de foliação da rocha e no contato do dos grãos de quartzo, favorecem a desagregação desses grãos e, consequentemente, a fase posterior de remoção por erosão em ambiente freático, conforme proposto por Martini 
(1979; 2004). O mesmo foi encontrado por Aubrecht et al. (2011) ao investigarem grandes sistemas de cavernas areníticas nos tepuis venezuelanos. Eles observaram que a dissolução de outros minerais silicatados além do quartzo, tais como mica e feldspato, parece representar papel fundamental no desenvolvimento dessas feições, atribuindo a formação do carste predominantemente à erosão, através do piping.

As pesquisas sobre o tema quase sempre destacam o papel da dissolução na formação de cavernas, sejam estas carbonáticas ou siliciclásticas. Ela é, em geral, citada associada à atuação de um conjunto de fatores, no qual intervêm além da taxa de dissolução, o tempo de realização das reações químicas, a composição mineralógica da rocha, além da presença da erosão (SAURO et al., 2013). Além desses, também interferem no processo de dissolução, os aspectos dinâmicos associados às condições morfogenéticas e de circulação da água relacionado ao estabelecimento de uma rede de drenagem subterrânea.

\subsection{O papel das descontinuidades do substrato geológico}

A carstificação não consiste apenas no processo de dissolução. Inclui, ainda, fatores hidrogeológicos que controlam e tornam possível o estabelecimento de uma rede subterrânea de circulação da água. Parece haver consenso entre vários autores a respeito do notável controle que as estruturas geológicas exercem no desenvolvimento das paisagens cársticas (SZCERBAN \& URBANI, 1974; URBANI, 1986a; GALÁN, 1991; WRAY, 1997b; GALÁN et al., 2004). Neste sentido, Galán (1991) aponta que a diferenciação entre a carstificação em rochas siliciciclásticas e carbonáticas decorre, sobretudo, do fato de que a dissolução não atua somente através da porosidade secundária da rocha, mas também ao longo das superfícies intercristalinas. Isso ocorre devido à lenta taxa de dissolução da sílica, que permite que a solução permaneça abaixo do nível de saturação por um longo tempo, atuando em espaços muito estreitos. As descontinuidades seriam, dessa maneira, importantes no processo, em especial nos quartzitos que apresentam baixa porosidade primária. As estruturas geológicas permitem a penetração da água superficial até o interior dos maciços rochosos, possibilitando uma progressiva arenização desde a superfície até grandes profundidades, bem como a formação de uma malha subterrânea composta por material friável
(WHITE et al., 1966; POUYLLEAU \& SEURIN, 1985; DOERR, 1999).

Segundo Wray (1997b), a maior parte das feições cársticas areníticas e quartzíticas (torres, corredores, abismos, dolinas e cavernas) possui gênese relacionada às estruturas da rocha. Isto explicaria o porquê das cavernas em rochas siliciclásticas se desenvolverem, em geral, nas bordas de escarpas, onde a descompressão da rocha tende a gerar fraturas mais abertas (MARTINI, 1979; GALÁN, 1991; WRAY, 1997b).

Jennings (1983) chama a atenção para a influência das estruturas no desenvolvimento de torres, corredores e cânions nos arenitos do noroeste da Austrália. Segundo o autor, a percolação da água, principalmente ao longo de juntas durante um período prolongado, resultou no desenvolvimento da paisagem ruiniforme da região. Essa interpretação é reforçada por Wray (2009), para quem, o desenvolvimento de um amplo sistema de condutos subterrâneos em terreno arenítico na região de Queensland na Austrália, não se procedeu inteiramente no domínio intergranular, mas devido a um conjunto de fatores que incluem a participação de juntas e acamamentos. Ele destaca que a presença de juntas verticais proeminentes permite uma rápida transmissão da água superficial para subsuperfície, onde juntas e acamamentos horizontais transportam o fluxo lateralmente em direção ao vale. De acordo com Wray (2010), a circulação hídrica seria também controlada pelas diferentes resistências ao intemperismo químico dentro dos próprios arenitos e quartzitos, como verificado nos tepuis da Gran Sabana.

O mesmo foi constatado nos tepuis venezuelanos, onde Galán (1991) descreve formas como cânions, torres e labirintos formados a partir de uma profunda rede de fraturas verticais, que promoveria a dissecação intensa do terreno. Urbani (1986b) atribui à grande densidade das fraturas, um papel importante no desenvolvimento, ainda na fase inicial, das cavernas quartzíticas no sul da Venezuela. Essas estruturas proporcionam a infiltração da água e, consequentemente, a dissolução em grandes profundidades podendo, eventualmente, estender-se lateralmente através de planos de estratificação.

Corrêa Neto \& Dutra (1997) e Silva (2004) indicam a importância dos planos estratigráficos na gênese das cavernas da Província Espeleológica Andrelândia, na região sul de Minas Gerais. Segundo esses autores, os planos de acamamento compostos principalmente por 
micas e granulometria mais fina, são mais susceptíveis ao intemperismo químico com relação aos quartzitos grosseiros, que constituem a maior parte do pacote litoestratigráfico local.

Fabri (2011) verificou que a espeleogênese das cavernas quartzíticas ocorre preferencialmente ao longo dos níveis estratigráficos ricos em sericita, que se encontram concordantes com a morfologia da vertente. Dessa forma, o fluxo de água, a princípio, se propaga do input representado por descontinuidades, tais como fraturas verticais e subverticais por onde a água em superfície infiltra na rocha em direção à subsuperfície, para output, ou seja, as nascentes.

No entanto, nem todos atribuem às estruturas um papel tão fundamental. Young (1988) reporta não ter encontrado evidências de que as fraturas exerçam influência na gênese dos carstes. Para ele, a dissolução pode atuar como um todo no maciço, produzindo feições devido às variações da permeabilidade primária da rocha. Também Wray (1997a) verificou que arenitos com alta porosidade efetiva exibem notáveis formas cársticas, ao passo que arenitos que apresentam poros intersticiais não conectados (baixa porosidade efetiva), são apenas intemperizados de forma discreta.

É evidente que existe uma relação entre a gênese de cavernas e estruturas da rocha. Porém não se trata de uma associação direta, uma vez que, na grande maioria dos casos, a simples presença dessas estruturas não gera cavernas. É importante destacar que, embora as descontinuidades representem planos preferenciais de penetração e dissolução da rocha, muitas vezes essas estruturas dependem de outros fatores que também favorecem o processo de formação de piping, e o de- senvolvimento de cavernas, tais como o intemperismo preferencial de certos minerais, que nem sempre se encontram homogeneamente distribuídos nas rochas.

\subsection{Processos de piping em carste de litologias siliciclásticas}

Apesar de ser mais observado em estudos de processos erosivos, principalmente no desenvolvimento de voçorocas em rochas graníticas (AUGUSTIN et al., 2001; AUGUSTIN \& ARANHA, 2006), o processo de piping em rochas siliciclásticas ainda não é muito conhecido. De acordo com Martini (1984), o piping consiste em remover mecanicamente partículas sólidas, resultando na formação de condutos que podem evoluir formando galerias subterrâneas em alguma parte do sistema (Figura 2).

Parece haver consenso no sentido de que duas condições seriam essenciais ao desenvolvimento da etapa erosiva em carstes silicicláticos: a disponibilidade hídrica e o alto gradiente hidráulico, sendo que ambas devem ocorrer de forma integrada (MARTINI, 1979; GALÁN, 1991; YOUNG et al., 1992; CORRÊA NETO, 1997; SILVA, 2004).

Assim como no carste carbonático, alguns autores destacam a importância da topografia como condição necessária para que a água circule, favorecendo a remoção mecânica das rochas siliciclásticas (MARTINI, 1979; GALÁN, 1991; PALMER, 1991). Enquanto nas rochas carbonáticas a dissolução, responsável pelo maior volume de material produzido após a fase evolutiva inicial de dissolução, é indicada como fundamental para o desenvolvimento de cavernas, em rochas siliciclásticas, o alto gradiente hidráulico tende a ser
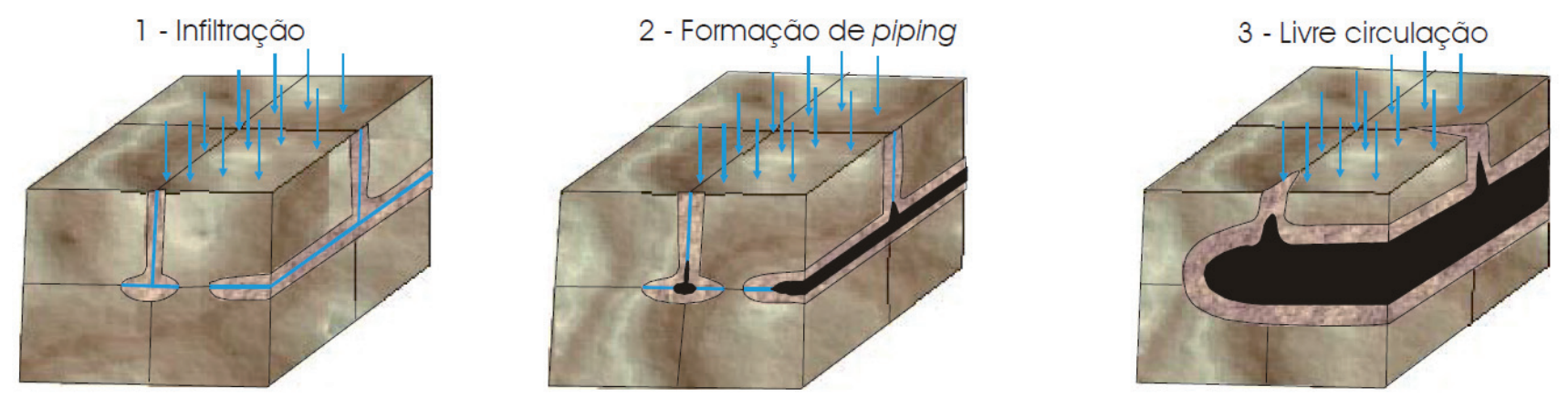

Quartzito coeso

Quartzito arenizado

Galeria da Caverna

Águas meteóricas

Figura 2 - Modelo de formação de condutos por arenização e piping. Fonte: Silva (2004) adaptado de Wiegand et al. (2004). 
considerado um dos fatores fundamentais na gênese das mesmas (GALÁN, 1991; CORRÊA NETO et al., 1997; WHITE, 1988; CORREAA NETO, 2000; SILVA, 2004).

Há situações nas quais outros fatores podem ser mais determinantes do que o gradiente no processo de cavernamento. Diferentemente do que foi constatado pelos autores citados acima, Fabri (2011) verificou que a ocorrência das cavernas quartzíticas de Itambé do Mato Dentro, não está intrinsecamente relacionada às áreas que apresentam maior gradiente hidráulico, mas aos quartzitos menos resistentes, que formam um relevo menos acidentado e com altitudes mais moderadas desta região. Já os quartzitos, mais resistentes, que compõem as serras de altitudes e declividade mais acentuadas, não favoreceram a formação de cavidades subterrâneas. Isto não significa afirmar que o gradiente encontra-se ausente, ou mesmo seja pouco significativo, no desenvolvimento dessas cavernas.

\section{A ocorrência do carste em rochas siliciclásticas no Brasil}

Durante um longo tempo acreditou-se que os quartzitos e arenitos não eram carstificáveis. Em decorrência disso, ainda hoje existem poucos registros de caráter mundial dessas formas de relevo. As quatro principais regiões geográficas que exibem formações de grande magnitude, consideradas referências na literatura, são os tepuis na Amazônia venezuelana, onde foram realizadas várias pesquisas, a península do Cape na África do Sul, a Austrália, sobretudo no noroeste das Kimberleys, e o Brasil (WHITE et al., 1966; SZCZERBAN \& URBANI, 1974; MARTINI, 1979, JENNINGS, 1983; URBANI, 1986b; YOUNG, 1988; WRAY, 1997a; SUGUIO, 1999; DOERR, 1999; GALÁN et al., 2004; PICCINI \& MECCHIA., 2009).

No Brasil, foi identificado o desenvolvimento de cavernas em arenitos e quartzitos ao longo de todo o território nacional e nos mais diferentes domínios morfológicos, desde a Amazônia até o sul do país (KARMANN et al., 1979; KARMANN et al., 1986; SUGUIO, 1999).

Nos tepuis brasileiros, localizados no noroeste do estado Amazonas, foi registrada a ocorrência da maior caverna de desenvolvimento vertical do Brasil, o abismo de Guy Collet com -670m de desnível (EPIS, 2007). Ainda no estado do Amazonas, Douglas et al. (1994) registraram cavernas em arenitos nas proximidades de
Manaus, no município de Presidente Figueiredo, e na região nordeste do estado, na Província do Arenito Alto Urubu- Uatumã. No estado do Pará, existem registros de duas províncias espeleológicas areníticas, a de arenito Monte Alegre e de quartzito Araguaia-Serra da Andorinha (SUGUIO, 1999).

No estado do Mato Grosso, na região da Chapada dos Guimarães, foi reportada a ocorrência de grutas desenvolvidas em arenitos das formações basais da Bacia Sedimentar do Paraná (BORGHI et al., 2002). Esta bacia conta, provavelmente, com uma das maiores regiões cársticas não-carbonáticas do Brasil. De acordo com Hardt e Pinto (2008), na região da Chapada dos Guimarães e Parecis está localizada uma das maiores cavernas em arenito do país, a gruta do Aroê-Jari, com comprimento superior a $1.500 \mathrm{~m}$.

Wernick et al. (1973) chamam a atenção para o fato de que na Serra Geral, que se estende do sul de Minas Gerais ao Rio Grande do Sul, há a ocorrência de cavidades nos arenitos Triássico-Jurássico da Formação Botucatu e Piramboia. Elas já eram conhecidas desde o final do Século XIX, e os primeiros trabalhos científicos sobre as mesmas foram publicados no final da década de 70, do século XX. Na Serra do Itaqueri, em Itapeúna - SP, são também registradas cavidades expressivas nesse tipo litologia (RIBEIRO et al., 1994).

Segundo Silva (2004), o estado de Minas Gerais é a região onde se tem conhecimento do maior número de ocorrência de formas cársticas desenvolvidas em rochas siliciclásticas no Brasil. A região se destaca não somente pela quantidade de cavernas registradas, mas também pela extensão das cavidades. A região sudeste de Minas Gerais, apresenta áreas espacialmente representativas de ocorrência de quartzitos, constituindo a Província Espeleológica Andrelândia (CORRÊA NETO et al., 1997), na qual são encontradas cavernas de grandes dimensões, nos municípios de São Tomé das Letras (MARQUES NETO, 2012), Carrancas e Luminárias. A Serra do Ibitipoca, no município de Lima Duarte, conta com um dos maiores potenciais cársticos nesta litologia na região, com cavernas bastante representativas, entre elas, a Guta das Bromélias, com desenvolvimento linear de 2.750 m (AULER, 2004; SILVA, 2004).

No Pico do Inficionado da Serra do Caraça, localizada na região sudeste do Quadrilátero Ferrífero, Minas Gerais, destaca-se a gruta do Centenário, com desenvolvimento linear superior a $4 \mathrm{~km}$. Esta gruta é 
considerada uma das maiores cavernas em termos de desenvolvimento vertical em quartzito do mundo. No entorno de Ouro Preto, MG, cavidades de menor porte foram estudadas no Serra do Itacolomi (WIEGAND et al., 2004).

Também na província do Espinhaço, que se estende desde as proximidades do município de Belo Horizonte até a região central da Bahia, estão localizadas grutas que já foram objeto de estudos. Entre elas, destaca-se a Gruta do Salitre, encontrada nos quartzitos Paleo/Mesoproterozóicos, em Diamantina, MG (BRICHTA et al., 1980). No sudeste da Serra do Espinhaço, estudo preliminar (CRUZ et al., 1999) revela a presença de cavernas desenvolvidas nos quartzitos da Serra Cabeça de Boi, no município de Itambé do Mato Dentro (MG). Outras cavernas foram identificadas na região de Itambé do Mato Dentro, entre as quais se destaca a Gruta Baixada das Crioulas, com projeção horizontal superior a $1 \mathrm{~km}$ (FABRI, 2011). Foram, da mesma maneira, identificadas feições cársticas nos arenitos eólico-fluviais da Formação Tombador, na Chapada Diamantina (WIEGAND et al., 2004).

Há evidências de território brasileiro abriga um conjunto ainda maior de feições cársticas em litologia siliciclástica, reportadas pela ocorrência de várias feições normalmente típicas de relevo em calcário como: dolinas, lapiás, torres, drenagem subterrânea e cavernas. Contudo, muitas delas ainda não foram estudadas, ou até mesmo cadastradas, o que é especialmente o caso das formas cársticas superficiais, que raras vezes foram objetos de pesquisa no Brasil (GENSER \& MEHL, 1977; BRICHTA et al., 1980; SALLUN FILHO \& KARMANN, 2007).

\section{Considerações Finais}

O termo carste é utilizado para designar regiões da superfície terrestre, cujo relevo é caracterizado por uma morfologia e hidrologia específicas, desenvolvido tanto em superfície como em subsuperfície, e resultante da circulação hídrica. A dissolução da rocha pela água, apesar de não ser necessariamente o fator dominante nesse sistema, é mais importante neste, do que em qualquer outro tipo de relevo.

Durante muito tempo associado ao relevo típico das regiões com substrato carbonático, o termo carste vem sendo, cada vez mais, utilizado para também desig- nar o relevo com formas semelhantes aquele, encontrado em outras litologias e que, até pouco tempo atrás, era enquadrado na terminologia geral de "pseudocarste". Essa apropriação do termo para outras litologias não constitui, contudo, um consenso entre os estudiosos, o que tem levado a discussões cada vez mais disseminadas sobre o real significado do mesmo. Há propostas, inclusive, do uso de outras denominações, como criocarste e vulcanocarste, para o relevo desenvolvido em rochas não carbonáticas, de maneira a melhor precisar, segundo os proponentes, os processos envolvidos.

Este é o caso do relevo oriundo do processo de dissolução das rochas siliciclásticas, que gera formas de relevo semelhantes àquelas das rochas carbonáticas. A aplicação do termo é ainda bastante debatida, uma vez que parte dos processos, e mesmo os fatores, envolvidos nessas esculturação não são totalmente conhecidos $\mathrm{e}$ entendidos. Alia-se a isto, o fato de que nem mesmo os mecanismos da dissolução da sílica em condições experimentais de laboratório ser totalmente entendidos, em especial, quando comparados com o que já se conhece sobre o intemperismo das rochas carbonáticas. Dessa maneira, pode-se assumir que ainda existem várias suposições no que se refere aos fatores e a maneira pela qual a dissolução da sílica ocorre, pois estes aspectos carecem de base experimental que os sustente.

Consensos importantes já foram, contudo alcançados. Um dos mais significativos é o reconhecimento da importância não somente da litologia da rocha, como também de outros fatores atuantes no desenvolvimento dessas feições, como as estruturas geológicas, além dos processos de intemperismo químico, mecânico e a erosão, entre outros.

Parte significativa das pesquisas mais recentes aponta como condições importantes na gênese das cavernas em rochas siliciclásticas, a disponibilidade hídrica e o tempo necessário para que ocorra a dissolução, em função da baixa solubilidade dessas rochas. Tendo em vista que o processo de dissolução aparentemente exige continuidade ao longo de muito tempo, assume-se que a estabilidade tectônica represente um fator determinante para que a carstificação se desenvolva. É também conhecido, entre os mecanismos identificados até agora, que a dissolução nessas litologias pode ocorrer preferencialmente em outros minerais mais solúveis que o quartzo, podendo até mesmo estar ausente neste mineral. 
Fatores de origem geológico-estrutural, entre eles, a presença de fraturas, juntas e planos estratigráficos, parecem favorecer a penetração da água de chuva e o seu condicionamento no meio subterrâneo, tornando possível sua disponibilidade para as trocas químicas. Porém, diferentemente do que se observa nas rochas carbonáticas, foi constatado que a dissolução é eficiente também nos pequenos espaços entre os grãos de quartzo, promovendo a desagregação dos mesmos.

Na literatura é destacada ainda a importância da fase erosiva através do processo de piping, que ocorre posteriormente à fase inicial, dominada por processos de dissolução, sendo que ela responderia pela maior remoção quantitativa dos resíduos insolúveis (grãos de quartzo). Neste contexto, deve-se realçar o papel do gradiente hidráulico como elemento necessário para que a água circule, favorecendo a dissolução e a remoção mecânica das rochas.

O Brasil é considerado um das quatro maiores províncias do mundo na ocorrência do carste em siliciclática, além da Venezuela, Austrália e África do Sul. Apesar disso, pouco ainda se conhece sobre o desenvolvimento desse tipo de relevo no país, e mesmo o seu cadastramento é pouco significativo. Considera-se, portanto, possível, que as áreas de ocorrência, e as condições para seu desenvolvimento, sejam ainda maiores e diversificadas do que atualmente se imagina.

A análise da presença de feições cársticas em diferentes litologias constitui uma abordagem relativamente recente e ainda com muitos aspectos controversos. No entanto, a identificação da presença dessas feições em uma variada gama de litologias e domínios climáticos, abriu novas possibilidades de pesquisa, indicando a necessidade de aprofundamento na compreensão dos fatores, processos e mecanismos envolvidos na esculturação desses relevos, incluindo, no Brasil, como realçado acima.

\section{Agradecimentos:}

À Fundação de Amparo à Pesquisa do Estado de Minas Gerais (FAPEMIG) pelo apoio financeiro (CRA-APQ 0165209) para esta pesquisa; Ao Instituto do Carste, BH-MG, pelo suporte para a realização da mesma.

\section{Referências Bibliográficas}

AUBRECHT, R.; LANCZOS, T.; GREGOR, M.; SCHLOGL, J.; SMIDA, B.; LISCAK, P.; BREWER-CARIAS, C.; VLCEK, L. Sandstone caves on Venezuelan tepuis: return to pseudokarst? Geomorphology, vol. 132, p. 351-365, 2011.

AUGUSTIN, C.H.R.R.; ARANHA, P.R.A.; ELMIRO, M.A.T.; MORATO, L. A ocorrência de pipes descontínuos em Gouveia, MG Brasil, detectados com o auxílio do Ground Penetrating Radar (GPR). X Congresso Latino Americano de Geologia/ Congresso Uruguaio de Geologia. Anais... Montividéo: Sociedad de Geologia, 2001, CDRom, 18p.

AUGUSTIN, C.H.R.R.; ARANHA, P.R.A. A ocorrência de voçorocas em Gouveia, MG: características e processos associados. Geonomos, vol. 14, nº1-2, p. 75 - 86, 2006.

AULER, A.S. Quartzites caves of South America. In: GUNN, J. (ed.), Encyclopedia of Caves and Karst Science. London: Fitzroy Dearbornp, 2004. p. 611-613.

BENNET, P.C. Quartz dissolution in organic-rich aqueous systems. Geochimica et Cosmochimica Acta, vol. 55, p. 17811797, 1991.

BENNET, P.C.; MELCER, M.E.; SIEGEL, D.I.; HASSET, J.P. The dissolution of quartz in dilute aqueous solutions of organic acids at $25^{\circ} \mathrm{C}$. Geochimica et Cosmochimica Acta, vol. 52, p. 1521-1530, 1998.

BORGHI, L.; MOREIRA, M.I.C. Caverna Aroe Jarí, Chapada dos Guimarães, MT - Raro exemplo de caverna em arenito. In: SCHOBBENHAUS, C.; CAMPOS, D.A.; QUEIROZ, E.T.; WINGE, M.; BERBERT-BORN, M.L.C. (eds), Sítios Geológicos e Paleontológicos do Brasil. Brasília: DNPM, 2002. p. 481-490.

BREHM, U.; GORBUSHINA, A.; MOTTERSHEAD, D. The role of microorganisms and biofilms in the breakdown and dissolution of quartz and glass. Geochimica et Cosmogeochimica Achta, vol. 219, p. 117-129, 2004.

BRICHTA, A.; PATERNOSTER, K.; SCHOLL, W.U.; TURINSKY, F. Die Gruta do Salitre bei Diamantina, Minas Gerais, Brasilien, Kein "Einsturzloch". Zeitschrift für Geomorphologie, vol. 24, p. 236-242, 1980.

CORRÊA NETO, A.V.; BATISTA FILHO, J. Espeleogênese em Quartzitos da Serra do Ibitipoca, sudeste de Minas Gerais. Anuário do Instituto de Geociências, vol. 20, p. 75-97, 1997. 
CORRÊA NETO, A.V.; DUTRA, G. A Província Espeleológica Quartzítica Andrelândia, sudeste de Minas Gerais. XXIV Congresso Brasileiro de Espeleologia, Ouro Preto, 1997. Anais ... Ouro Preto: Sociedade Brasileira de Espeleologia, 1997. p. 57-64.

CORRÊA NETO, A.V. Speleogenesis in Quartzites from Southeastern Minas Gerais, Brazil. In: KLIMCHOUK, B.A.; FORD, D.C.; PALMER, A.N.; DREYBRODT, W. (ed.) Speleogenesis - Evolution of Karst Aquifers. Huntsville (USA): National Speleologica Society, 2000. p. 452 - 457.

CRUZ, L.V.; PEREIRA FILHO, M.; LOPES, M.V.C.O.; MOURÃO, R.C. Avaliação Espeleológica da Serra Cabeça de Boi, Fazenda Ponte-Itambé do Mato Dentro-MG. XXV Congresso Brasileiro de Espeleologia. Anais... EcoSubterrâneo. 1999. p. 27-38.

DOERR, S.H. Karst-like landforms and hydrology in quartzites of the Venezuelan Guyana Shield: Pseudokarst or "real" Karst? Zeitschrift für Geomorphologie, vol. 43, p. 1-17, 1999.

DOUGLAS, J.; FERREIRA, T.; VIEIRA, L.; COSTA, G.; SARGES, R.; FERREIRA, R.; BEZERRA, R.; ANDRADE, N.; SILVA, R.; RUIZ, A.C. A caverna arenítica do Maragora - Presidente Figueredo, AM: Observações e considerações. XXXVIII Congresso Brasileiro de Geologia. Anais... Camboriú (SC): Sociedade Brasileira de Geologia, 1994. p. 395-396.

DREVER, J.I.; STILLINGS, L.J. The role of organic acids in mineral weathering. Colloids and Surfaces, vol. 120, p. 167$181,1996$.

EPIS, L. Expedição Amazonas. Campinas: Informativo SBE, vol. 92, p. 30-36, 2007.

FABRI, F.P. Estudo das cavernas quartzíticas da região de Itambé do Mato Dentro. Belo Horizonte, 2011. 179f. Dissertação de Mestrado em Geografia - Instituto de Geociências, Universidade Federal de Minas Gerais, BH-MG.

FABRI, F.P.; AUGUSTIN, C.H.R.R. Fatores e processos envolvidos no desenvolvimento de formas cársticas em rochas siliciclásticas em Minas Gerais, Brasil. Geografias, vol. 9, $\mathrm{n}^{\circ}$ $1,2013$.

GALÁN, C. Disolución y gênesis del karst en rocas carbonáticas y rocas silíceas: un estudio comparado. Munibe, vol. 43, p. 43-72, 1991.

GALÁN, C.; HERRERA, F.F.; CARREÑO, R. Geomorfologia e Hidrologia del Sistema Roraima Sur, Venezuela, La mayor cavidad del en cuarcitas: $10,8 \mathrm{~km}$. Bol. Soc. Venezoelana Espeleol.,vol. 38, p. 2-16, 2004.
GENSER, H.; MEHL, J. Einsturzlocher in silikatischen Gesteinen Venezuelas und Brasiliens. Zeitschrift für Geomorphologie, vol. 21, p. 431-444, 1977.

GLAZEK, J. Karst related phenomena - the Problem of proper Nomenclature. 9th International Symposium on Pseudokarst, 24-26 May 2006. Proceedings... Bartkowa, Beskidy Mts, Poland: Institute of Nature Conservation, 2006. p. 47-48.

GONÇALVES, F.; RODET, J.; OLIVEIRA, D.C.; MAGALHÃES JR., A.P. Cavidades em granitos no munícipio de Santa Maria Madalena - RJ (Brasil). 31 ${ }^{\circ}$ Congresso Brasileiro de Espeleologia, 21-24 de julho de 2011. Anais... Ponta Grossa-PR: Sociedade Brasileira de Espeleologia, 2011. p. 87-93.

HARDT, R.; PINTO, S.A.F. Carste em rochas não carbonáticas. Revista Brasileira de Geomorfologia, vol 10, Especial, n.2, p. 99-105, 2009.

HARDT, R.; RODET, J.; WILLEMS, L.; PINTO, S.A.F. Exemplos Brasileiros de Carste em Arenito: Chapada dos Guimarães (MT) e Serra de Itaqueri (SP). Espeleo-Tema, vol. 20, no 1-2, p. 7-23, 2009.

HENDERSON, P. Inorganic geochemistry. New York: Pergamon Press, 1982. 353p.

ICEHOWER, J.; DOVE, P. The dissolution kinetics of amorphous silica into sodium chloride solutions: Effects of temperature and ionic strength. Geochimica et Cosmochimica Acta, vol. 64, n 24, p. 4193-4203, 2000.

JENNINGS, J.N. Sanstone pseudokarst or karst? In: YOUNG, R.W.; NANSON, G.C. (eds.). Aspects of Australian Sandstone Landscapes. Wollongong : University of Wollongong: Australian and New Zealand Geomorphology Group Special Publication, Edition 1, p. 21-30, 1983.

KARMANN, I.; SANCHEZ, L.E. Distribuição das rochas carbonáticas e províncias espeleológicas do Brasil. EspeleoTema, vol. 13, p. 105-167, 1979.

KARMANN, I., SANCHEZ, L.E. Speleological Provinces in Brazil. $9^{\circ}$. CONGRESO INTERNACIONAL DE ESPELEOLOGIA. Anais.... Barcelona: IUS, 1986, vol. 1, p. 151-153.

KRAUSKOPF, K.B. Introdução à Geoquímica. São Paulo: Polígono/Edusp, vol. 1. 1972.

LUNDBERG, J.; BREWER - CARIAS, C.; McFALARNE, D.A. Preliminary results from U-Th dating interglacial deposition cycles in a silica speleothem from Venezuela. Quaternary Research, vol. 74, p. 113-120, 2010a. 
LUNDBERG, J.; BREWER - CARIAS, C.; McFALARNE, D.A. An extraordinary example of photokarren in a sandstone cave, Cueva Charles Brewer, Chimantá Plateau, Venezuela: Biogeomorphology on a small scale. Geomorphology, vol. 121, p. $342-357,2010$ b.

MARQUES NETO, R. O fenômeno cárstico em são Thomé das Letras (MG). Revista Brasileira de Geomorfologia, vol. 13, $n^{\circ} 4$, p. 443-450, 2012.

MARTINI, J. Karst in the Black Reef Quartzite near Kaapsehoop, Transvaal. Ann. Geol. Surv. South Africa, vol. 13, p. 115-128, 1979.

MARTINI, J. Rate of quartz dissolution and weathering of quartzite. Bulletin of the South African Spelaeological Association, vol. 25, p. 7-10, 1984.

MARTINI, J. Silicate Karst. In: GUNN, J. (ed.): Encyclopedia of Caves and Karst Science. New York: Taylor and Francis Group, 2004. p. 1385-1392.

MECCHIA, M.; PICCINI, L. Hidrogeology and $\mathrm{Si}_{2}$ geochemistry of the Aonda Cave System, Auyan-Tepui, Bolivar, Venezuela. Boletin de la Sociedad Venezolana de Espeleologia, vol. 33, p. 1-11, 1999.

MELO, M.S.; GIANNINI, P.C.F. Sandstone dissolution landforms in the Furnas Formation, Southern Brazil. Earth Surface Processes and Landforms, vol. 32, p. 2149-2164, 2007.

PALMER, A.N. Origin and morphology of limestone caves. Geological Society of America Bulletin, vol. 103, p. 1-21, 1991.

PICCINI, L.; MECCHIA, M. Solution weathering rate and origin of karst landforms and caves in the quartzite of Auyantepui (Gran Sabana, Venezuela). Geomorphology, vol. 106, p. 15-25, 2009.

POUYLLAU, M. Les karsts greseux dans la Gran Sabana (Guyane Vénézuélienne). Bull. Assoc. Géogr. Franç., vol. 62, p. 269-283, 1985.

POUYLLAU, M.; SEURIN, M. Pseudo-karst dans les roches gréso-quartzitiques de la formation Roraima. Karstologia, vol. 5, p. 4 5-52, 1985.

RENAULT, P. Caractères généraux des grottes gréseuses du Sahara méridional. I Congrés International de Spéléologie, 7-12 September 1953. Proceedings.... Paris: Comité Nacional de Spéléologie, France, 1953. p. 275-289.

RIBEIRO, L.F.B.; VANDEROOST, F.J.; MONTEIRO, R.C. $\mathrm{O}$ controle neotectônico das cavernas de Itaqueri. XXXVIII Congresso Brasileiro de Geologia. Anais... Camburiu, SC:
Sociedade Brasileira de Geologia, 1994. p. 397-399.

ROMANÍ, J.R.V.; BOURNE, J.A.; TWIDALE, C.R.; CAMPBELL, E.M. Siliceous cylindrical speleothems in granitoids in warm semiarid and humid climates. Zeischrift für Geomorphologie N.F., vol. 47, nº.4, p. 417-437, 2003.

ROMANÍ, J.R.V.; VAQUEIRO, M. Types of granite cavities and associated speleothems: genesis and evolution. Nature Conservation, vol. 63, p. 41-46, 2007.

SALLUN FILHO, W.; KARMANN, I. Dolinas em arenito da Bacia do Paraná: evidências de carste subjacente em Jardim (MS) e Ponta Grossa (PR). Revista Brasileira de Geociências, vol. 37, p. 551-564, 2007.

SAURO, F.; PICCINI, L.; MECCHIA, M.; de WAELE, J. Comment on "Sandstone caves on Venezuelan tepuis: Return to pseudokarst?" by R. Aubrecht, T. Lánczos, M. Gregor, J. Schlögl, B. Smída, P. Liscák, C. Brewer-Carías, L. Vlcek, Geomorphology, vol. 197, 190-196, 2013.

SELF, C.A.; MULLAN, G.J. Redefining the boundary between karst and pseudokarst. Cave and Karst Science, vol. 23, p. 63-70, 1996.

SILVA, S.M. Carstificação em Rochas Siliciclásticas: Estudo de caso na Serra do Ibitipoca, Minas Gerais. MG. 2004. $143 f$. Dissertação de Mestrado em Geografia, Instituto de Geociências, Universidade Federal de Minas Gerais, BH-MG.

SUGUIO, K. O relevo cárstico e a geoespeleologia. In: Geologia do Quaternário e mudanças ambientais: passado + presente = Futuro? Paulo's Comunicação e Artes Gráficas, p. 219-232, 1999.

SZCZERBAN, E.; URBANI, F. Carsos de Venezuela. Parte 4: Formas carsicas en areniscas precambrianas del territorio federal Amazonas y estado Bolivar. Boletin de la Sociedade Venezolana de Espeleologia, vol. 5, p. 27-54, 1974.

TWIDALE C.R. Sinkholes (Dolines) in lateritised sedimentes, Western Stuart Plateau, Northern Territory, Australia. Geomorphology, vol. 1, p. 33-52, 1987.

UAGODA, R; AVELAR, A.; COELHO NETTO, A.L. Karstic morphology control in non-carbonate rocks: Santana basin, middle Paraiba do Sul river valley, Brazil. Zeitschrift für Geomorphologie, vol. 55, $\mathrm{n}^{\circ}$ 1, 2011, p. 1-13.

URBANI, F. Notas sobre el origen de las cavidades en rocas cuarciferas precambrianas del Grupo Roraima, Venezuela. Interciencia, vol. 11, p. 298-300, 1986a.

URBANI, F. Una revision preliminar sobre el desarrollo de 


\section{Relevo Cárstico em Rochas Siliciclásticas: Uma Revisão com Base na Literatura}

cavidades y otras formas relacionadas en las rocas cuarciferas del Grupo Roraima, Guayana Venezolana. Parte 2. Algunos comentarios sobre terminologia. Boletin de Geociencias, vol. 7, p. 10-14, 1986b.

TRICART, J.; CAILLEUX, A. Introduction to Climatic Geomorphology. London: Longmans, 1972. 295 p.

VIERS, J.; DUPRÉ, B.; POLVÉ, M.; SCHOTT, J.; DANDURAND, J.; BRAUN, J. Chemical weathering in the basin of a tropical watershed (Nsimi-Zoetele site, Cameroon): comparison between organic- poor and organic rich waters. Chemical Geology, vol. 140, p. 181-206, 1997.

VILES, H.; PENTECOST, A. Problems in asessing the weathering action of lichens with an example of epiliths on sandstone. In: ROBINSON, D.A., WILLIANS, R.B.G. (eds). Rock Weathering and Landform Evolution. London: John Wiley \& Sons Ltd, 1994. p. 99-116.

WERNICK, E.; PASTORE, E.L.; PIRES NETO, A. Cavernas em arenito. Notícia Geomorfológica, vol. 13, p. 55-67, 1973.

WHITE, W.B. Geomorphology and Hydrology of Karst Terrains. Oxford: Oxford University Press, 1988. 464p.

WHITE, W.B.; JEFFERSON, G.L.; HAMAN, J.F. Quartzite Karst in southeastern Venezuela. International Journal of Speleology, vol. 2, p. 309-314, 1966.

WIEGAND, J.; FEY, M.; HAUS, N.; KARMANN, I. Investigações Geoquímicas e hidroquímicas da gênese de carste em arenitos e quartzitos da Chapada Diamantina e Quadrilátero Ferrífero (Brasil). Z. Dt. geol. Ges., vol. 155, p. 61-90, 2004.

WILLEMS, L.; COMPERE, P.; SPONHOLZ, B. Study of siliceous karst genesis in eastern Niger: microscopy and X-ray microanalysis of speleothems. Zeitschrift für Geomorphologie, vol. 42, p. 129-142, 1998.

WRAY, R.A.L. A global review of solutional weathering forms on quartz sandstones. Earth-Science Reviews, vol. 42, p. 137160, 1997a.

WRAY, R.A.L. The formation and significance of coralline silica speleothems in teh Sidney Basin, southeastern Australia. Physical Geography, vol. 18, p. 1-17, 1997b.

WRAY, R.A.L. Quartzite dissolution: Karst or pseudokarst? Cave and karst Science, vol. 24, p. 81-86, 1997c.

WRAY, R.A.L. Phreatic drainage conduits within quartz sandstone: Evidence from the Jurassic Precipice Sandstone, Carnarvon Range, Queensland, Australia. Geomorphology, vol. 110, p. 203-211, 2009.

WRAY, R.A.L. The Gran Sabanas: the world's finest quartzite karst? In: MIGÓN, P. (ed.). Geomorphological Landscapes of the World. London: Springer Verlag, 2010. p. 79-88.

YARIV, S.; CROSS, H. Geochimistry of Colloid Systems for Earth Scientists. Berlin: Springer-Verlag, 1979. 450p.

YOUNG, R.W. Quartz etching and sandstone Karst: Examples from the East Kimberleys, northwestern Australia. Zeitschrift fur Geomorphologie, vol. 32, p. 409-423, 1988.

YOUNG R.W; YOUNG, A.R.M. Sandstone Landforms. Berlin: Springer-Verlag, 1992. 163p.

YOUGER, P.L.; STUNELL, J.M. Karst and pseudokarst: An artificial distinction? In: BROWN, A.G. (ED.), Geomorphology and Groundwater, London: Willey \& Sons, 1995. p. 121-142. 